\title{
3-D Petrography of a Diamondiferous Eclogite from Udachnaya, Siberia
}

\author{
Keller, Randall A. ${ }^{1}$, Taylor, Lawrence A. ${ }^{1}$, Snyder, Gregory A. ${ }^{1}$, Sobolev, Vladimir S. ${ }^{1}$, Carlson, \\ William D. ${ }^{2}$, Sobolev, Nikolai V. ${ }^{3}$, and Pokhilenko, Nikolai P. ${ }^{3}$ \\ 1Planetary Geosciences Institute, University of Tennessee, Knoxville, TN, 37996, USA; rkeller@utk.edu \\ ${ }^{2}$ Department of Geological Sciences, University of Texas, Austin, TX, 78712, USA \\ ${ }^{3}$ Institute of Mineralogy and Petrography, Russian Academy of Sciences, Novosibirsk 630090, Russia
}

\section{Introduction}

The environment in which diamonds form is preserved in diamondiferous xenoliths, but this environment has never been fully examined in three dimensions. We are conducting a detailed analysis of a diamond assemblage in situ in an eclogite xenolith to establish the timing and conditions of diamond crystallization. This addresses one of the fundamental questions of diamond genesis: Did these diamonds crystallize at the same time as their host rock (i.e., are they igneous), or are they associated with a later metasomatic fluid event (i.e., metamorphic)? Our approach is a complete characterization of the 3-D texture of a $4 \times 5 \times 6 \mathrm{~cm}$ eclogite xenolith from the Udachnaya kimberlite (Yakutia) using high-resolution X-ray computed tomography (HRXCT; Denison et al., 1997; Rowe et al., 1997), followed by dissection of the xenolith and detailed examination and chemical analyses of the diamonds, their inclusions, and the associated eclogite host minerals.

\section{Tomography \& 3-D Petrography}

The entire volume of eclogite xenolith U51-3 was scanned in a series of 79 X-ray slices (Figure 1) at a slice thickness of $0.5 \mathrm{~mm}$, using a microfocal X-ray source operating at $100 \mathrm{kV}$ and $0.4 \mathrm{~mA}$.

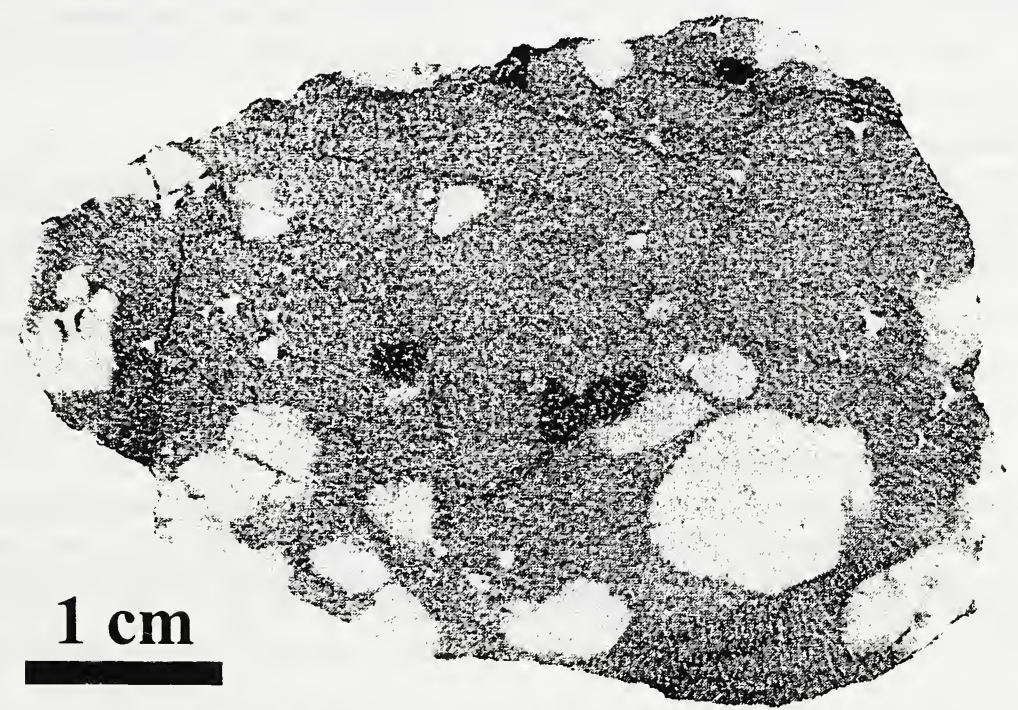

Figure 1. A tomographic "slice" through the diamondiferous eclogite shows diamonds (dark gray to black shapes near the center and top edge of the image), sulfides (small white spots), and garnets (light gray shapes) in a matrix of clinopyroxene (medium gray) with a linear alteration fabric (seen as slightly darker gray lines). The entire volume of the sample was scanned in a series of 79 of these X-ray slices. Darkness in this grayscale image inversely corresponds with a combination of density and mean atomic number. The diamonds are easily distinguished from the other minerals using this technique, whereas previous XCT experiments on a diamondiferous rock (Schulze et al., 1996) resolved diamonds only where they were surrounded by a high-density mineral (barite). 
This provided optimum contrast between the minerals present, and in-plane resolution of approximately $0.25 \mathrm{~mm}$. Beam-hardening artifacts were minimized by embedding the sample in powdered garnet, and correcting for absorption measured in a scan through the powder alone. The HRXCT clearly resolved the diamonds in this sample and the textural details of their surrounding mineral assemblages. Stacking the 79 HRXCT slices into a three-dimensional digital model of the xenolith allows us to view spatial relationships between the diamonds, textural relationships between the diamonds and the eclogite, and calculate volume percentages of minerals.

The sample is $0.5 \%$ macro-diamonds by volume, or approximately 25,000 carats/tonne. Eleven diamonds with maximum dimensions of up to $4 \mathrm{~mm}$ are visible on the exterior of the sample, and HRXCT revealed an additional 19 diamonds in the interior. Ten of the 30 diamonds abut kelyphytic rims of garnets, but the diamonds are never enclosed within a garnet or clinopyroxene crystal, consistent with the interpretation that the diamonds postdate the silicate minerals. Most of the diamonds are associated with the prominent fabric of alteration veins (visible in hand-sample and in the HRXCT data), which is also consistent with a secondary origin for the diamonds. An alternative explanation is that the rock was preferentially altered around the diamonds. This may be possible because of the large difference in compressibility between diamonds and silicate minerals. Differential expansion could have localized stress at the diamonds, causing the rock to preferentially fracture and more easily alter around the diamonds.

The remainder of the xenolith consists of $31 \%$ red-orange garnets $\left(\mathrm{Gr}_{9} \mathrm{Py}_{58} \mathrm{Al}_{32}\right)$ up to $1 \mathrm{~cm}$ in diameter and $1 \%$ Fe-Ni sulfides up to $3 \mathrm{~mm}$ in diameter, all dispersed in a variably altered matrix of dark green (where unaltered) clinopyroxene (Wo37 $\mathrm{En}_{49} \mathrm{Fs}_{14} ; \mathrm{Na}_{2} \mathrm{O}-5.5$ wt.\%) that makes up 68\% of the sample. All of the garnets have kelyphytic rims, but are otherwise fresh. Clinopyroxene occurs as inclusions in garnet, and vice versa. Sulfides occur as inclusions in garnet and clinopyroxene. There are no systematic differences between garnets and clinopyroxenes that abut diamonds and those that do not.

\section{Inclusions in Diamonds}

Nearly all of the diamonds in this eclogite contain numerous mineral inclusions. Sulfide inclusions are ubiquitous, whereas clinopyroxene inclusions are far less abundant, and garnets are rare. Many inclusions less than $20 \mu \mathrm{m}$ in size also occur, but have not been positively identified.

Two 50-100 $\mu \mathrm{m}$ clinopyroxene inclusions from crack-free regions of two separate diamonds have compositions similar to clinopyroxene in the host xenolith except that the inclusions have distinctly lower $\mathrm{Na}_{2} \mathrm{O}$ (4.5 wt.\% vs. 5.5 wt.\%) and higher $\mathrm{K}_{2} \mathrm{O}(0.2 \mathrm{wt} . \%$ vs. $<0.1$ wt.\%) than the host (Figure 2). This same phenomenon was observed by Taylor et al. (1996) in other eclogitic diamond inclusions from Udachnaya. Higher $\mathrm{K}_{2} \mathrm{O}$ in the clinopyroxene inclusions is consistent with crystallization at a higher pressure (Harlow and Veblen, 1991) and suggests that the clinopyroxenes in the host were partially melted or re-equilibrated at a lower pressure after the diamonds formed.

\section{Conclusion}

Apart from minor re-equilibration at lower pressure, clinopyroxene in this eclogite xenolith has changed little since the time that the diamonds crystallized. We take this as evidence that this xenolith is a well-preserved sample of the environment in which eclogitic diamonds form. That every single one of the 30 diamonds in this xenolith is associated with alteration is compelling evidence for the interpretation that the diamonds crystallized during a metasomatic event. 


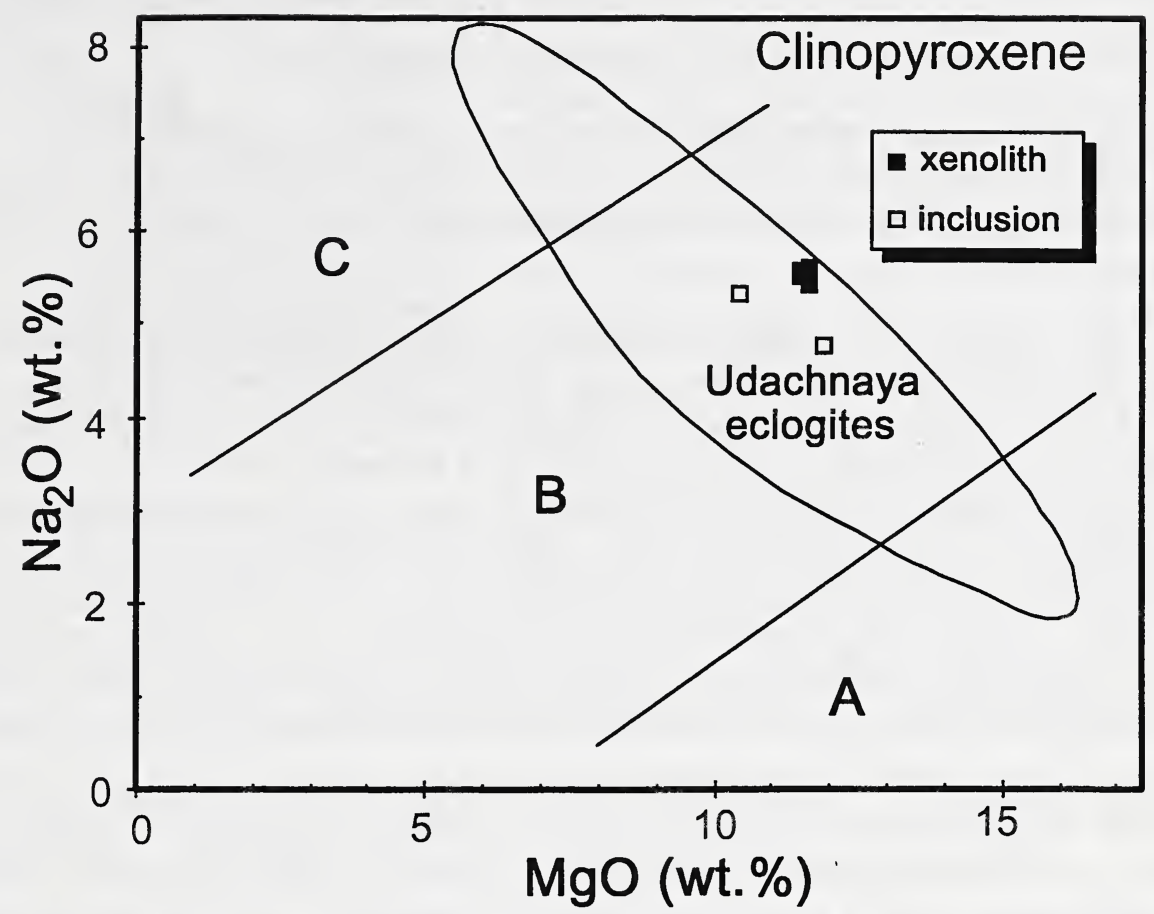

Figure 2. Clinopyroxene inclusions in diamonds from eclogite U51-3 have lower $\mathrm{Na}_{2} \mathrm{O}$ contents and lower to slightly higher $\mathrm{MgO}$ contents than clinopyroxenes in the eclogite host. Both the host and the inclusions plot within the field for Group B eclogites, which is consistent with data for the majority of Udachnaya (field from Sobolev et al., 1994). Group boundaries are from Taylor and Neal (1989).

\section{References}

Denison, C., Carlson, W.D., and Ketcham, R.A., 1997, Three-dimensional quantitative textural analysis of metamorphic rocks using high-resolution computed X-ray tomography: Part I. Methods and techniques: J. Metam. Geol., 15, p. 29-44.

Harlow, G.E., and Veblen, D.R., 1991, Potassium in clinopyroxene inclusions from diamonds: Science, 251, p. 652655.

Rowe, T., J. Kappelman, W.D. Carlson, R.A. Ketcham, and C. Denison, 1997, High-resolution computed tomography: A breakthrough technology for earth scientists: Geotimes, Sept. 1997, p. 23-27.

Schulze, D.J., D. Wiese, and J. Steude, 1996, Abundance and distribution of diamonds in eclogite revealed by volume visualization of CT X-ray scans: J. Geol., 104, p. 109-114.

Sobolev, V.N., Taylor, L.A., Snyder, G.A., and Sobolev, N.V., 1994, Diamondiferous eclogites from the Udachnaya kimberlite pipe, Yakutia. Int. Geol. Rev.: 36, p. 42-64.

Taylor, L.A., and Neal, C.R., 1989, Eclogites with oceanic crustal and mantle signatures from the Bellsbank kimberlite, South Africa, part I: Mineralogy, petrography, and whole rock chemistry: J. Geol., 97, p. 551-567.

Taylor, L.A., Snyder, G.A., Crozaz, G., Sobolev, V.N., and Sobolev, N.V., 1996, Eclogitic inclusions in diamonds: Evidence of complex mantle processes over time: Earth Planet. Sci. Lett., 142, p. 535-551. 